\title{
Impact Analysis of Trim Tab Inclination Angles Variation to Propulsion Power Requirement of 6 Meter's Speed Boat
}

\author{
Amiadji ${ }^{1}$, Achmad Baidowi ${ }^{2}$, Aufal Nanda Oktova ${ }^{3}$ \\ (Received: 27 August 2021 / Revised: 10 September 2021 / Accepted: 22 September 2021)
}

\begin{abstract}
-determining the ship's propulsion power requirements is one of the most crucial things in ship design which is related to the ship's resistance. One of the causes of the high value of a ship's resistance is excessive trim of the ship. Therefore it needs a mechanism to overcome this, it can be by applying trim tabs. The trim tab is a small surface mounted on the ship's transom that can be adjusted according to the conditions of the ship. By adjusting the angle of the trim tab to be larger, it can increase the lift force and torque moment at the stern of the ship which can reduce the trim of the ship. Based on the boat's characteristics, referring to the guide from Bennet Marine, the appropriate trim tab's geometry for this boat is a trim tab with a span width of 18 " $(46 \mathrm{~cm})$ and a chord length of 9 " $(23 \mathrm{~cm})$. After selecting the trim tab geometry, then analyzing the resistance and trim of the ship using the CFD method. Through CFD simulation, trim tab with an angle of $15^{\circ}$ can reduce the value of the ship's resistance to $17.25 \%$ and for the trim can be reduced to $46.72 \%$. Then after the ship's propulsion power requirements calculation, it is shown that the trim tab with an angle of $15^{\circ}$, a reduction of $11.56 \%$ is obtained from $78.854 \mathrm{~kW}$ to $69.741 \mathrm{~kW}$.
\end{abstract}

Keywords_CFD, Propulsion Power, Ship Resistance, Trim, Trim Tab.

\section{INTRODUCTION}

$\mathrm{S}_{\mathrm{n}}$ hip resistance is one of the important factors in ship planning. By study of Deddy Chrismanto and Berlian Arswendo (2014) that the total resistance of the ship can affect the total required engine power [1]. Frictional resistance is one of the main components of the largest ship resistance ranging from $60 \%-70 \%$. With a significant reduction in frictional resistance, it can reduce fuel consumption [2].

One of the causes of the increase in the value of frictional resistance is due to excessive trim at the stern of the ship. In addition, variations in trim can cause instability in the form of porpoising on fast boats [3].

Referring to research by Maria Margareta Z.B. (2016) discusses the effect of the trim tab angle on a 60 meter fast patrol boat using the CFD approach. It was found that the installation of trim tabs can reduce the turbulence that occurs at the stern of the ship. In addition, with the installation of trim tabs on the transom of the ship, it causes torsional moments and lift forces [4].

Therefore, it's necessary a system that is installed on the ship that functions to minimize the occurrence of excessive trim and porpoising especially at high speed operation. One method to overcome this is by installing trim tabs which are the most widely used devices both in

Amiadji, Departmen of Marine Engineering, Institut Teknologi Sepuluh Nopember, Surabaya 60111, Indonesia.

E-mail : amiadji@its.ac.id

Achmad Baidowi, Departmen of Marine Engineering, Institut Teknologi Sepuluh Nopember, Surabaya 60111, Indonesia. E-mail : ahmadbai@gmail.com

Aufal Nanda Oktova, Departmen of Marine Engineering, Institut Teknologi Sepuluh Nopember, Surabaya 60111, Indonesia. E-mail : aufaloktova0610@gmail.com the planning hull and also can be applied to aircraft wings [3].

The installation of the trim tab on a 6-meter speed boat expected will reduce the ship's resistance and excessive trim values and can reduce the required propulsion power of the ship.

\section{METHOD}

In this study, the method that will be used is the simulation method. In particular, this research will focus on the comparison of ship resistance, trim, and ship propulsion required on speed boats before and after trim tab installation. For a detailed explanation, it will be explained below :

\section{A. Identification of Problems}

Identification, problem formulation, and research objectives are carried out first so that research can be directed. The topic in this study is about the impact of the trim tab angle on the propulsion power requirement of a 6 meter speed boat. Simulation of ship resistance and trim speed boat 6 meters using the CFD method. Then from the resistance of the ship, the required ship propulsion power is calculated using the approximate formula.

\section{B. Data Collection}

To support the research, it takes some data that contains the main data of the ship including:

- 3D Model

- General Arrangement

- Construction Profile

\section{Weight Calculation}

The weight of the ship is calculated by the post per post method and is divided into several parts including the hull, superstructure, construction, equipment and deadweight of the ship. The calculation of the weight of the ship can be seen in the following table. 
TABLE 1.

WEIGHT CALCULATION

\begin{tabular}{|c|c|c|c|c|c|}
\hline \multirow{2}{*}{ No } & \multirow{2}{*}{ Item } & \multirow{2}{*}{$\begin{array}{c}\text { Weight } \\
(\mathrm{kg})\end{array}$} & \multirow{2}{*}{$\frac{\text { LCG }}{(\mathrm{m})}$} & \multirow{2}{*}{$\frac{\text { VCG }}{(\mathrm{m})}$} & \multirow{2}{*}{$\frac{\text { TCG }}{\text { (m) }}$} \\
\hline & & & & & \\
\hline 1 & HULL & 380.57 & 2.02 & 0.34 & 0.00 \\
\hline 2 & SUPERSTRUCTURE & 249.32 & 2.44 & 0.61 & 0.00 \\
\hline 3 & CONSTRUCTION & 97.29 & 3.32 & 1.27 & 0.00 \\
\hline 4 & FO TANK & 245.00 & 1.75 & 0.15 & 0.00 \\
\hline 5 & EQUIPMENT AND OUTFITTING & 288.08 & 0.93 & 0.57 & 0.00 \\
\hline 6 & PAX & 810 & 2.202 & 0.676 & 0.00 \\
\hline 7 & LUGGAGE & 90 & 2.202 & 0.676 & 0.00 \\
\hline & TOTAL & 2160.268 & 2.028 & 0.563 & 0.00 \\
\hline
\end{tabular}

\section{Model Validation}

To get high accuracy between simulation and real data, a validation process is carried out. In this study, validation was carried out by comparing the vessel resistance and trim on each different number of cells. This process showed good results with a percent error of not more than $2.46 \%$

\section{E. Trim Tab Addition}

Before the CFD simulation, the trim tab was added to the ship's hull. The trim tab is installed on the transom of the ship and is installed according to the shape of the transom of the ship. To determine the geometry of the trim tab size, use parameters including ship length and main engine configuration. After obtaining the geometry trim tab, the next step is to vary the angle which will be used in the simulation process. Trim tabs are varied at angles of $5^{\circ}, 10^{\circ}$ and $15^{\circ}$.

\section{F. CFD Simulation}

Simulation using CFD NUMECA FINE MARINE software is carried out by simulating 4 ship models (1 bare hull model and 3 variations of trim tab angle model) with 3 speed variations including 15 knots, 17 knots, and 19 knots. So the total simulation is 12 times.

As shown in Figure 1, in the hull meshing process, the thing that needs to be considered is to add a refinement box in the form of a sector made around the ship. This is because in the case study of speed boats, occurred extreme pitching and porpoising movements. Therefore, it is necessary to add a refinement box to prevent negative volume errors during the running process. In addition, another thing that needs to be considered in the meshing process is the addition of the number of refinements in the trim tab area to obtain meshing details in that area.

In this study, the solver process was carried out using an unsteady time configuration on 2 fluid media including air and seawater with a temperature of $19^{\circ} \mathrm{C}$. Therefore, the point to consider is the input inertia matrix on the body motion parameter. Then in the boundary condition parameters, all surfaces on the ship are defined as solid wall functions except for the surface deck defined as slip.

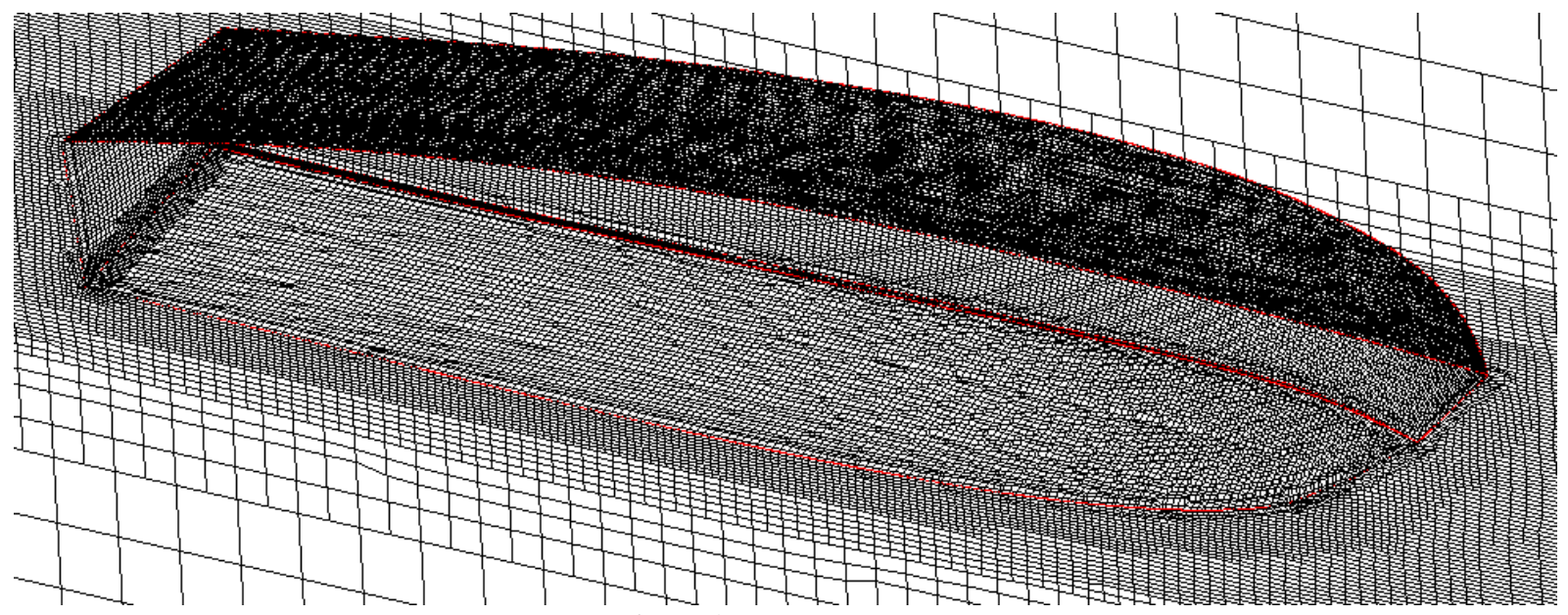

Figure. 1. Meshed Half Body.

\section{G. Ship Propulsion Power Calculation}

The last step is the calculation of the propulsion power required for the speed boat. Calculations are carried out using an approximation formula based on references from Sv.Aa. Harvard (1983) [5], J. S. Carlton (2012) [6] and Edward V. Lewis (1988) [7] with the following steps :

- Effective Horse Power 


$$
\mathrm{EHP}=\mathrm{Rt} \times \mathrm{Vs}
$$

- Wake Friction

$$
\mathrm{w}=(0.5 \times \mathrm{cb})-0.05
$$

- Thrust Deduction Factor

$$
\mathrm{t}=\mathrm{kxw}
$$

- $\quad$ Speed of Advance

$$
\mathrm{Va}=(1-\mathrm{w}) \mathrm{x} \mathrm{Vs}
$$

- Hull Efficiency

$$
\eta \mathrm{h}=(1-\mathrm{t}) /(1-\mathrm{w})
$$

- $\quad$ Propulsive Coefficient

$$
\mathrm{Pc}=\eta \mathrm{h} \times \eta \mathrm{rr} \times \eta \mathrm{o}
$$

- Thrust Horse Power

$$
\mathrm{THP}=\mathrm{EHP} / \eta \mathrm{h}
$$

- Delivered Horse Power

$$
\mathrm{DHP}=\mathrm{EHP} / \mathrm{PC}
$$

- $\quad$ Shaft Horse Power

$$
\mathrm{SHP}=\mathrm{DHP} / \eta \mathrm{s} \eta \mathrm{b}
$$

- $\quad$ Brake Horse Power (SCR)

$$
\mathrm{BHPscr}=\mathrm{SHP} / \eta \mathrm{g}
$$

- $\quad$ Brake Horse Power (MCR)

$$
\mathrm{BHPmcr}=\mathrm{BHPscr} / 0.85
$$

\section{RESULTS AND DISCUSSION}

\section{A. Trim Tab Geometry Addition}

In the selection of this trim tab, it is determined by several parameters including the length of the ship, the configuration of the main engine, and the availability of space in the ship's transom. Based on the guide, the trim tab is obtained with a span width of 18 " $(46 \mathrm{~cm})$ and a chord length of 9" $(23 \mathrm{~cm})$. Then proceed with modeling along with variations in angles by referring to trim tab installation instructions as shown in Figure 2.

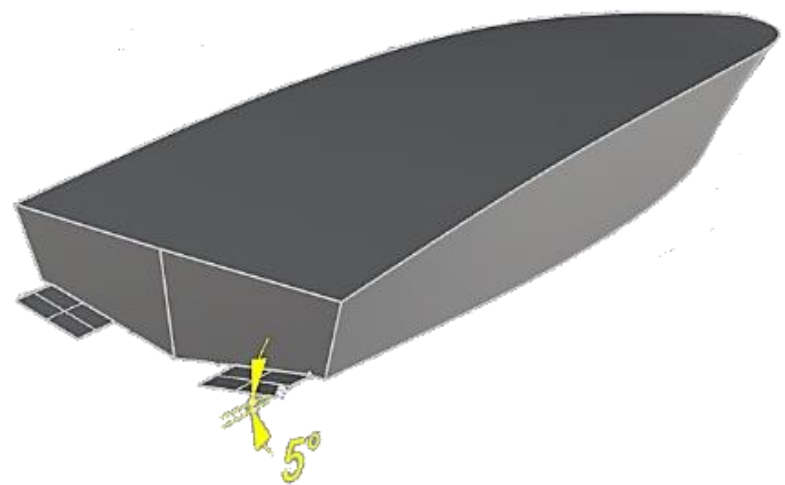

(Figure 2.b)

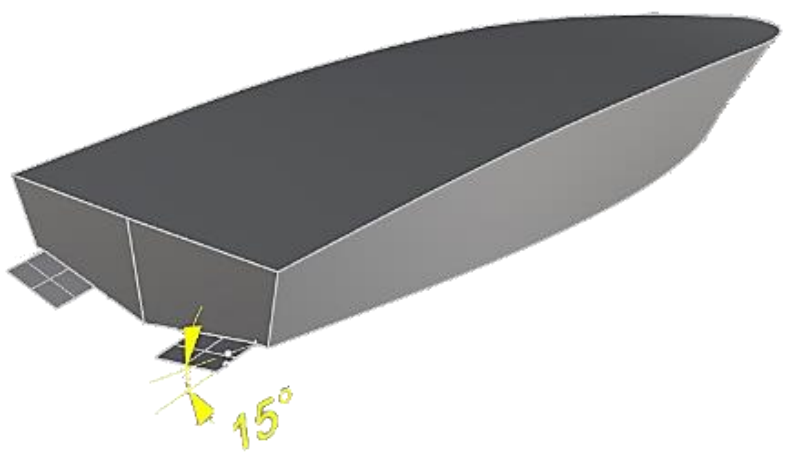

(Figure 2.d)

(Figure 2.c)

(c) Trim Tab $10^{\circ}$ (d) Trim Tab $15^{\circ}$

\section{B. Simulation Result}

The discussion on the results of the CFD simulation will be explained in several parameters including ship resistance, trim, wave elevation, hydrodynamic pressure, and relative velocity which will be reviewed based on variations in the model made.

\section{Ship Resistance}

In the discussion of the results of the first CFD simulation, it is to compare the results of the ship's resistance before and after the installation of the trim tab and its slope variations. From the simulation results, it is found that the higher the speed of the ship, the smaller the resistance value. This is because the object discussed in this study is a ship with planning hull characteristics. Where the hull can lift on the surface of the water when the ship is moving at high speed.

Based on the simulation results in Table 2 and Figure 3 , it was found that in all variations of the trim tab angle, both $5^{\circ}, 10^{\circ}$, and $15^{\circ}$, it showed a significant reduction in the total ship resistance value. At Fn 1.006; ship resistance is reduced by $17.25 \%$. Then at Fn 1.140; the ship resistance was reduced by $11.98 \%$ and at the 
condition of Fn 1.274; ship resistance was reduced by $11.56 \%$. From the discussion, it was found that the superior ship model based on the value of the ship's resistance is the ship model with a trim tab angle of $15^{\circ}$.

TABLE 2

SHIP RESISTANCE SIMULASTION RESULT

\begin{tabular}{ccccc}
\hline Model & Fn & Ship Resistance $(\mathrm{kN})$ & Reduction $(\mathrm{kN})$ & $\%$ \\
\hline \multirow{3}{*}{ Bare Hull } & 1.006 & 3.872 & 0.000 & $0.00 \%$ \\
& 1.140 & 3.588 & 0.000 & $0.00 \%$ \\
& 1.274 & 3.444 & 0.000 & $0.00 \%$ \\
\hline \multirow{2}{*}{ Trim Tab 5 deg } & 1.006 & 3.562 & 0.310 & $8.01 \%$ \\
& 1.140 & 3.334 & 0.254 & $7.08 \%$ \\
Trim Tab 10 deg & 1.274 & 3.170 & 0.274 & $7.96 \%$ \\
\hline \multirow{2}{*}{ Trim Tab 15 deg } & 1.006 & 3.368 & 0.504 & $13.02 \%$ \\
& 1.274 & 3.220 & 0.368 & $10.26 \%$ \\
& 1.006 & 3.064 & 0.380 & $11.03 \%$ \\
\hline
\end{tabular}

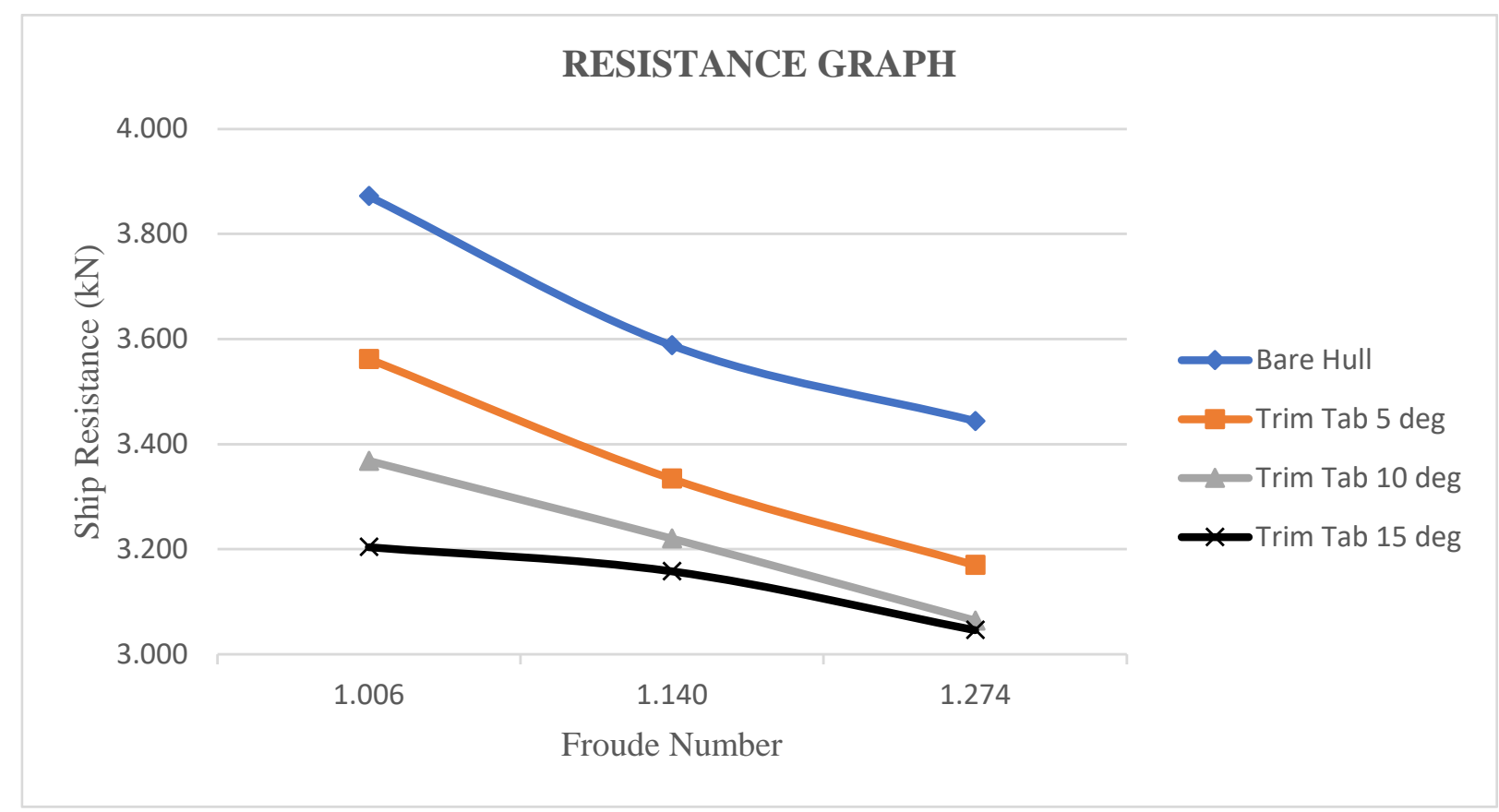

Figure. 3. Ship Resistance Graph.

\section{Trim Angle}

The trim angle of the ship is measured with respect to the center of gravity of the ship. Based on the simulation results in Table 3 and Figure 4, it was found that after installing the trim tab and the angle of inclination, it showed a significant reduction in the trim value of the ship. In the condition of Fn 1.006, the trim value of the ship has changed by $46.72 \%$. Then in the condition of Fn 1,140 , the trim value of the ship has changed by $40.53 \%$, and finally in the condition of Fn 1,274, the trim value of the ship has changed by $42.73 \%$. From the analysis based on the following ship trim values, it was found that the best trim angle reduction occurred at $15^{\circ}$ trim tab conditions. 
TABLE 3.

TRIM ANGLE SIMULATION RESULT

\begin{tabular}{ccccc}
\hline Model & Fn & Trim (deg) & Reduction (deg) & $\%$ \\
\hline \multirow{2}{*}{ Bare Hull } & 1.006 & 8.976 & 0.000 & $0.00 \%$ \\
& 1.140 & 8.013 & 0.000 & $0.00 \%$ \\
& 1.274 & 7.526 & 0.000 & $0.00 \%$ \\
\hline \multirow{2}{*}{ Trim Tab 5 deg } & 1.006 & 7.589 & 1.387 & $15.45 \%$ \\
& 1.140 & 7.048 & 0.965 & $12.04 \%$ \\
& 1.274 & 6.284 & 1.242 & $16.50 \%$ \\
\hline \multirow{2}{*}{ Trim Tab 10 deg } & 1.006 & 6.314 & 2.662 & $29.66 \%$ \\
& 1.140 & 5.916 & 2.097 & $26.17 \%$ \\
& 1.274 & 5.439 & 2.087 & $27.73 \%$ \\
\hline \multirow{2}{*}{ Trim Tab 15 deg } & 1.006 & 4.782 & 4.194 & $46.72 \%$ \\
& 1.140 & 4.765 & 3.248 & $40.53 \%$ \\
\hline
\end{tabular}

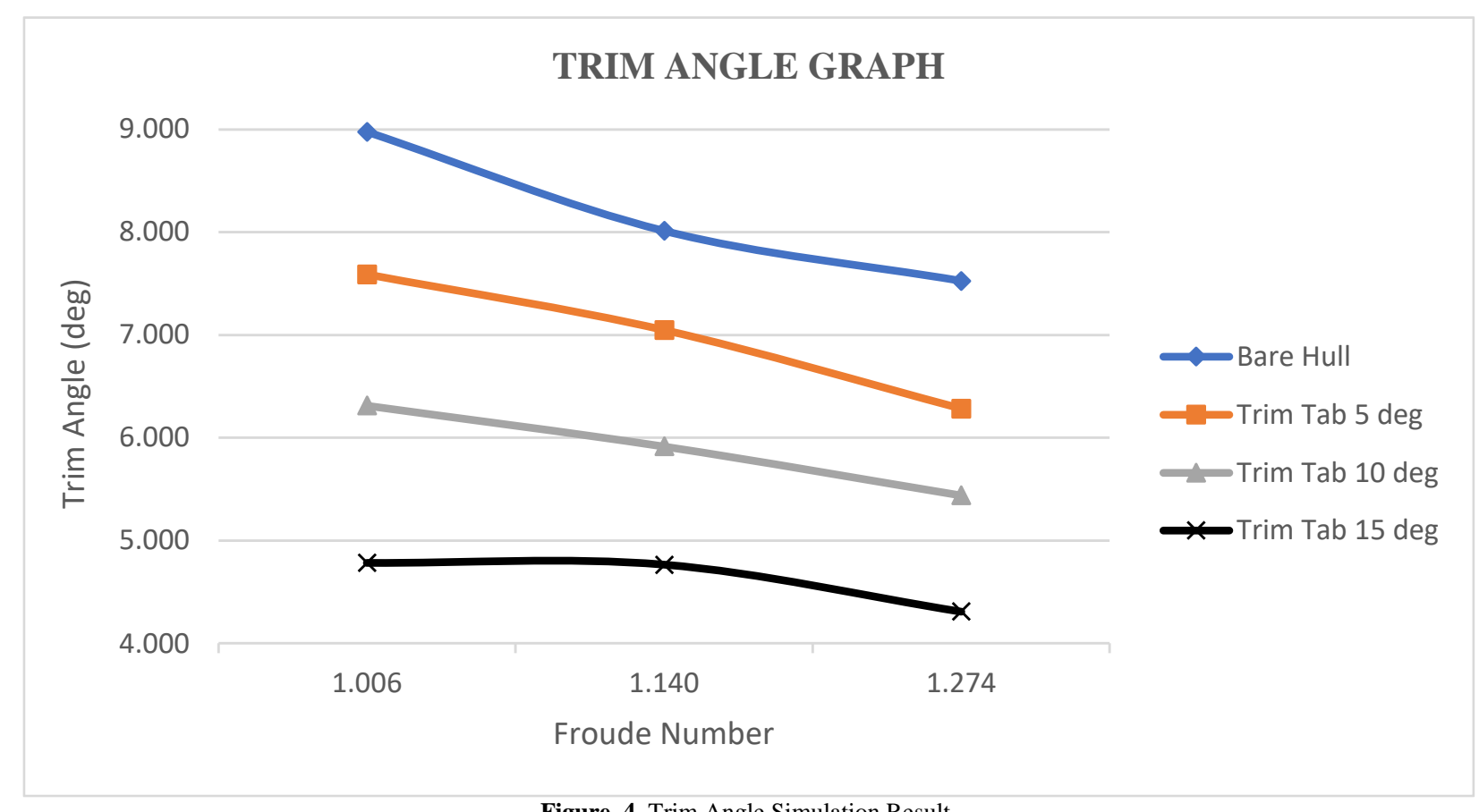

Figure. 4. Trim Angle Simulation Result.

3. Wave Elevation

As it is known that one of the coefficients of the ship's resistance is the result of the formation of waves due to the movement of the ship. Therefore, by identifying the wave pattern generated by the ship, it can be seen the effect of adding a trim tab to the ship's resistance.

Based on the simulation results at a speed of 15 knots or Fn 1.006 in Figure 5, it was found that in the bare hull condition, the wave pattern at the stern of the ship tends to be irregular with a height of $0.85 \mathrm{~m}$. In contrast to the
$5^{0}$ trim tab condition, the wave pattern looks straighter and the maximum wave height is reduced to no more than $0.7 \mathrm{~m}$. Then on the trim tab $10^{\circ}$, the waveform tends to be the same as the previous condition, but the resulting wave height can be reduced to $0.65 \mathrm{~m}$. Furthermore, in the $15^{\circ}$ trim tab condition, the stern of the ship is mostly dominated by blue and light blue which indicates the low waves generated in the range of 0.2 to $0.3 \mathrm{~m}$. 

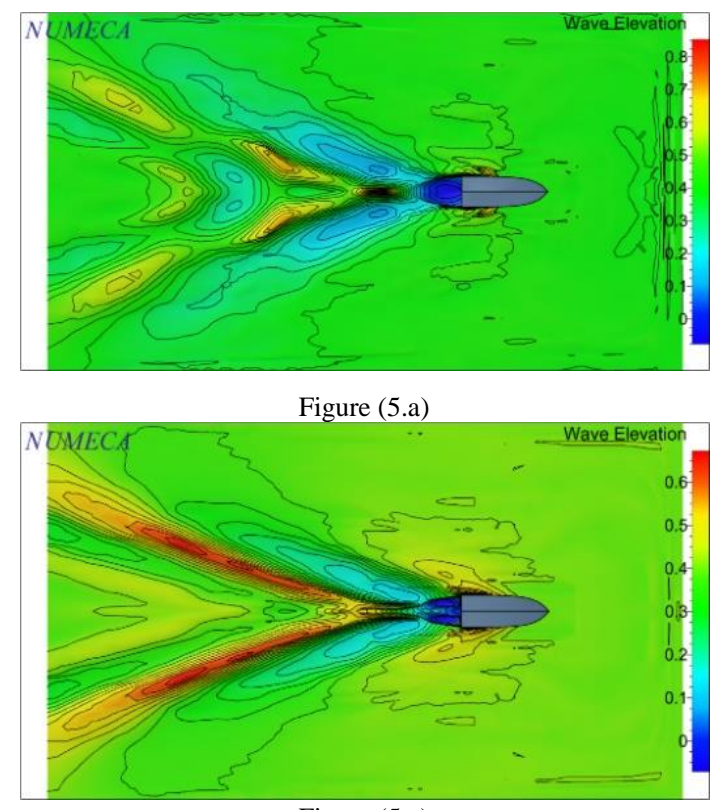

Figure (5.c)
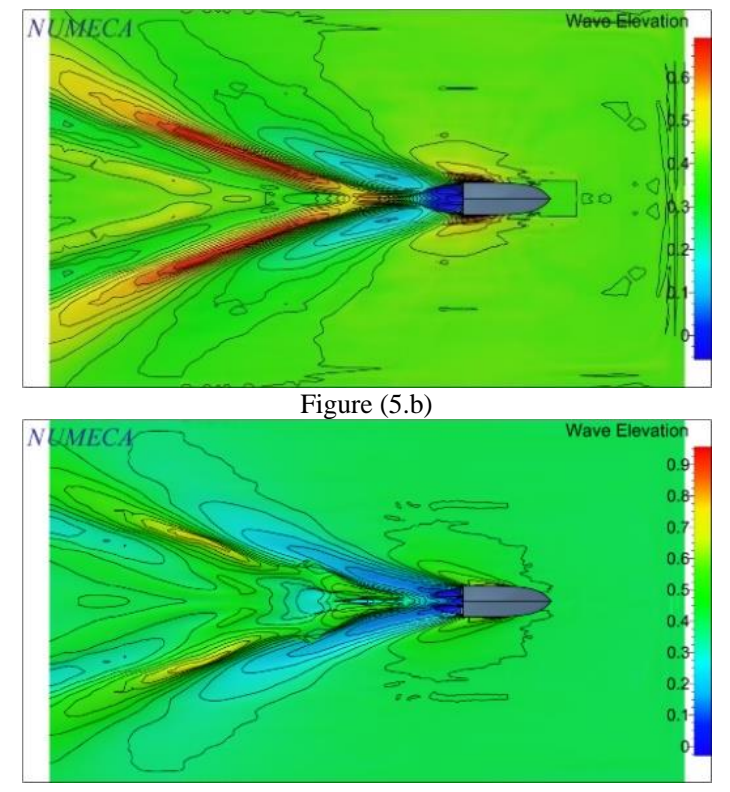

Figure (5.d)

Figure. 5. Wave Elevation at Fn 1.006 (a) Bare Hull (b) Trim Tab 50 (c) Trim Tab $10^{\circ}$ (d) Trim Tab $15^{\circ}$.

And for the simulation results at speed of 19 knots or Fn 1.274 in Figure 6, it is found that in the bare hull, the waves that appear at the stern of the ship are very high reaching $>0.7 \mathrm{~m}$ and the wave movement tends to widen compared to the condition after the addition of the trim tab. The addition of trim tabs at the stern of the ship and the angle of inclination can affect the wave pattern of the ship for the better. From these values, it can be said that the greater the angle of the trim tab can reduce the
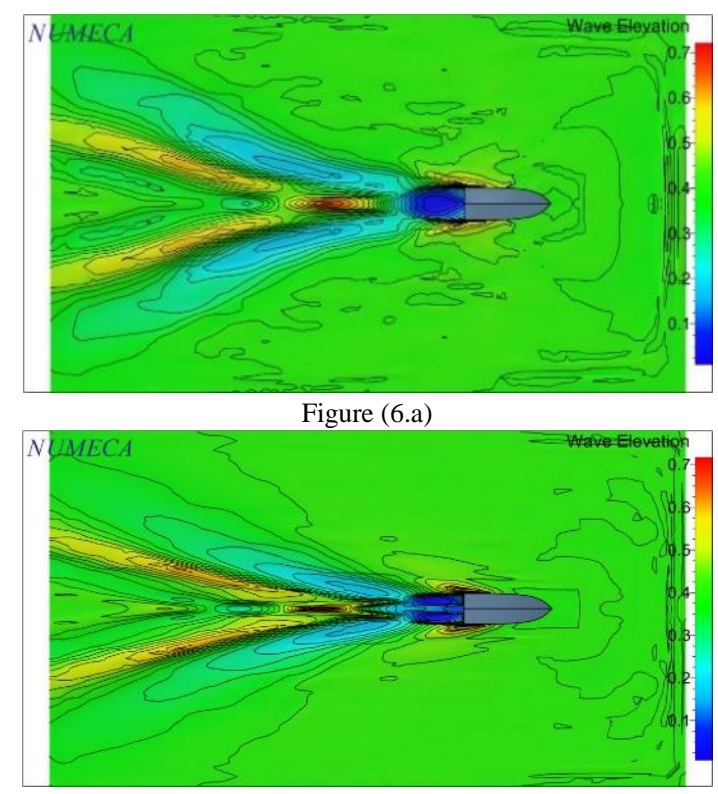

Figure (6.c)

Figure. 6. Wave Elevation at Fn 1,274 (a) Bare Hull (b) Trim Tab $5^{\circ}$ (c) Trim Tab $10^{\circ}$ (d) Trim Tab $15^{\circ}$.

\section{Hydrodynamic Pressure}

With the addition of trim tabs, it can cause an increase in pressure on the stern of the ship, especially in the area of adding trim tabs [6]. This can be proven by obtaining the hydrodynamic pressure value from the ship simulation results.

Based on the simulation at a speed of 15 knots or Fn 1.006 in Figure 7, it is show that in the bare hull maximum wave height that occurs at the stern of the ship. In the $5^{\circ}$ and 10 trim tab conditions, the maximum wave height that arises at the stern of the ship is still above $0.7 \mathrm{~m}$, but on the $15^{\circ}$ trim tab condition, there is a reduction in the maximum wave height that is generated, which is $0.675 \mathrm{~m}$. From this discussion, it can be seen that the best wave height reduction is in the trim tab $15^{\circ}$ condition.
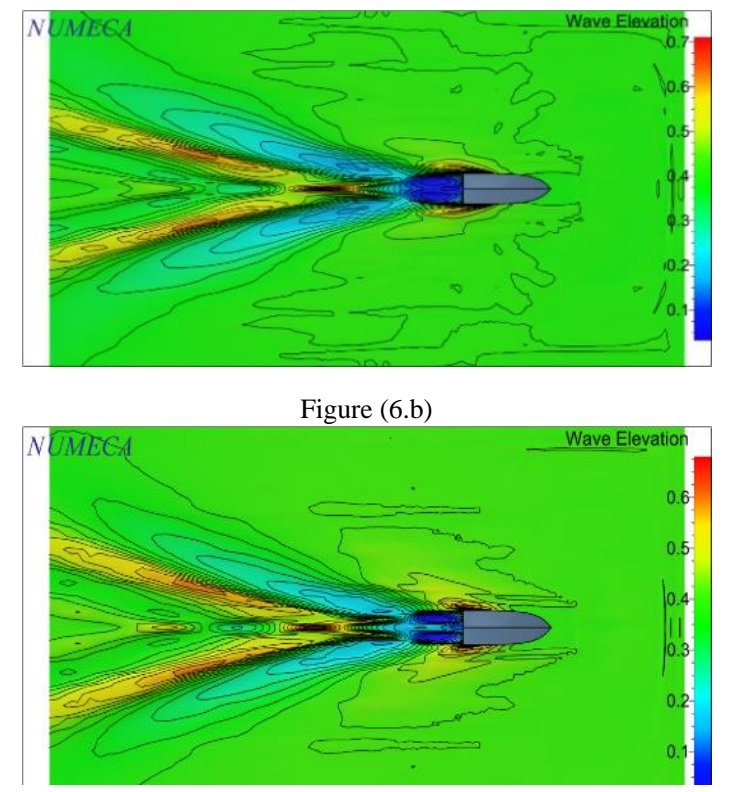

Figure (6.d) condition, the high pressure distribution is dominated by the hull section of the ship with the highest pressure reaching $>4000 \mathrm{~Pa}$. Not much different from the previous condition, in the $5^{\circ}$ trim tab the highest pressure is still dominated by the hull, while the trim tab area is dominated by yellow with a pressure value of around $2000 \mathrm{~Pa}$. 
While in the condition of the trim tab $10^{\circ}$, the red color on the hull faded slightly and there was an increase in pressure in the trim tab area which indicated the presence of high pressure on the trim tab with a maximum pressure reaching $>5000 \mathrm{~Pa}$. Then in the condition of the

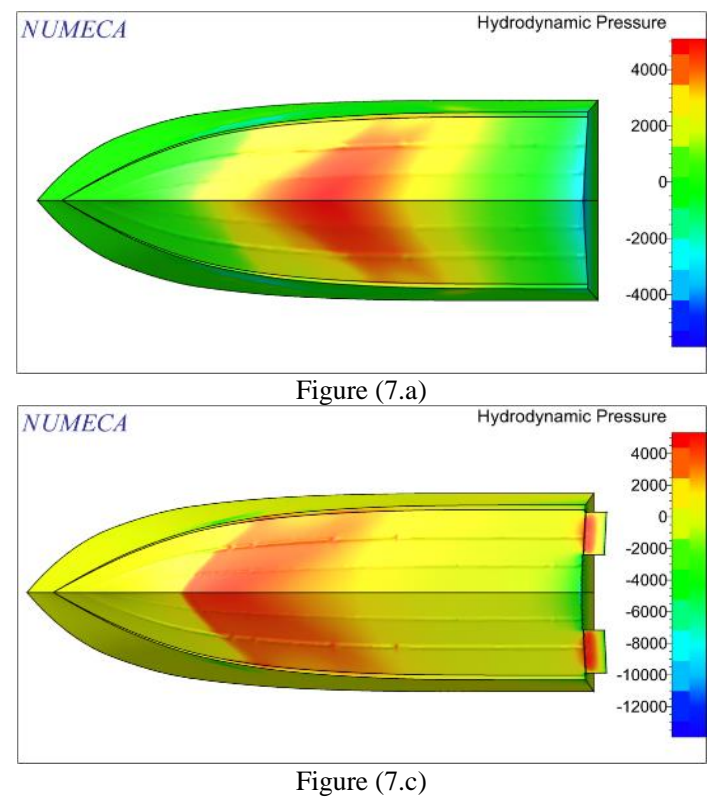

Figure. 7. Hydrodynamic Pressure at Fn 1.006 (a) Bare Hull (b) Trim Tab $5^{\circ}$ (c) Trim Tab $10^{\circ}$ (d) Trim Tab $15^{\circ}$.

And based on the simulation results at a speed of 19 knots or Fn 1.274 in Figure 8, it was found that in the bare hull condition, the pressure focused on the hull with a value of $>4000 \mathrm{~Pa}$. Likewise in the condition of the $5^{\circ}$ trim tab, a large increase in the value of the pressure that arises in the trim tab area reaches $6000 \mathrm{~Pa}$ while on the hull it can reach $8000 \mathrm{~Pa}$. The highest pressure is still

\section{Relative Velocity}

The working principle of the trim tab is based on the

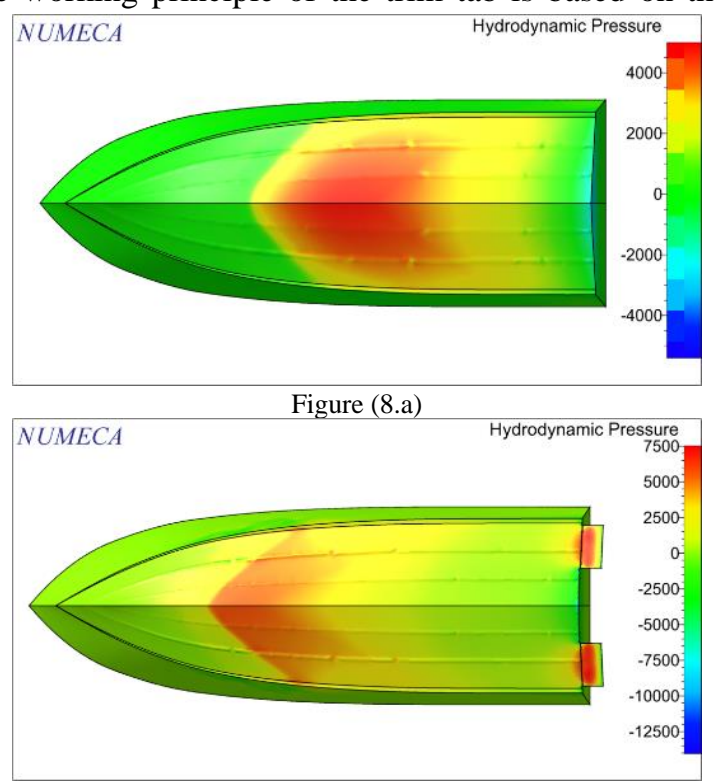

Figure (8.c)
Figure (8.d)
Figure. 8. Hydrodynamic Pressure at Fn 1.274 (a) Bare Hull (b) Trim Tab $5^{\circ}$ (c) Trim Tab $10^{\circ}$ (d) Trim Tab $15^{\circ}$.

eddy / fluid vortex that is formed in the area around the trim tab. The fluid vortex is caused by the trim tab blocking the flow of water at the bottom of the ship. trim tab $15^{\circ}$, it was shown that the red area on the hull did not dominate much and shifted to focus on the trim tab area and there was a fairly high pressure increase up to $>7500 \mathrm{~Pa}$.

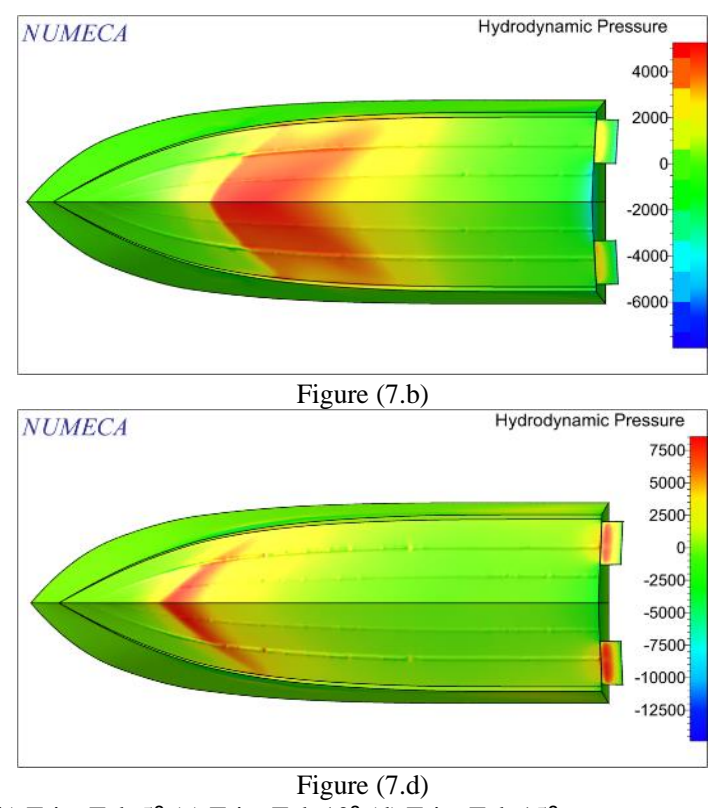

focused on the hull which is due to this condition the angle formed is still relatively small.

While in the condition of the $10^{\circ}$ trim tab, there is a red color in the trim tab area which indicates an increase in pressure which reaches $7500 \mathrm{~Pa}$. Likewise, the greater the angle of the trim tab, which is at an angle of $15^{\circ}$, the pressure is focused on the trim tab area and there is a significant increase in pressure reaching $10000 \mathrm{~Pa}$. With the vortex causes a lift force on the ship so as to minimize the occurrence of excessive stern trim and

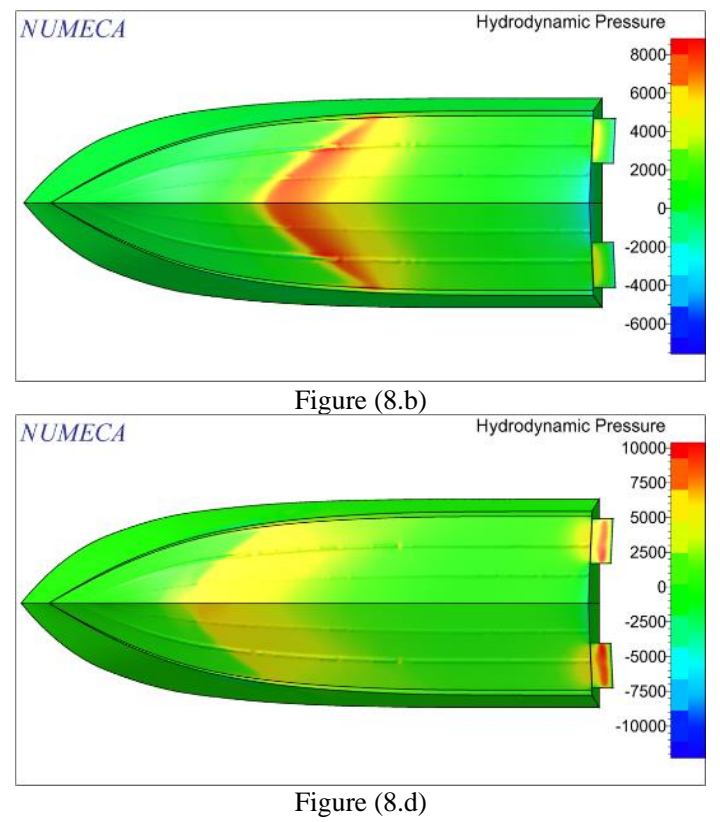

reduce the value of the ship's resistance.

Based on the simulation at a speed of 15 knots or Fn 1.006 in Figure 9, it was found that in the bare hull the 
flow velocity around the stern of the ship tends to be constant, identified from the green color that is evenly distributed from the hull to the ship's stern. While in the condition of the $5^{\circ}$ trim tab, there is a blue but not dominating color that appears around the trim tab area. This indicates a reduction in the flow velocity that appears in the area.

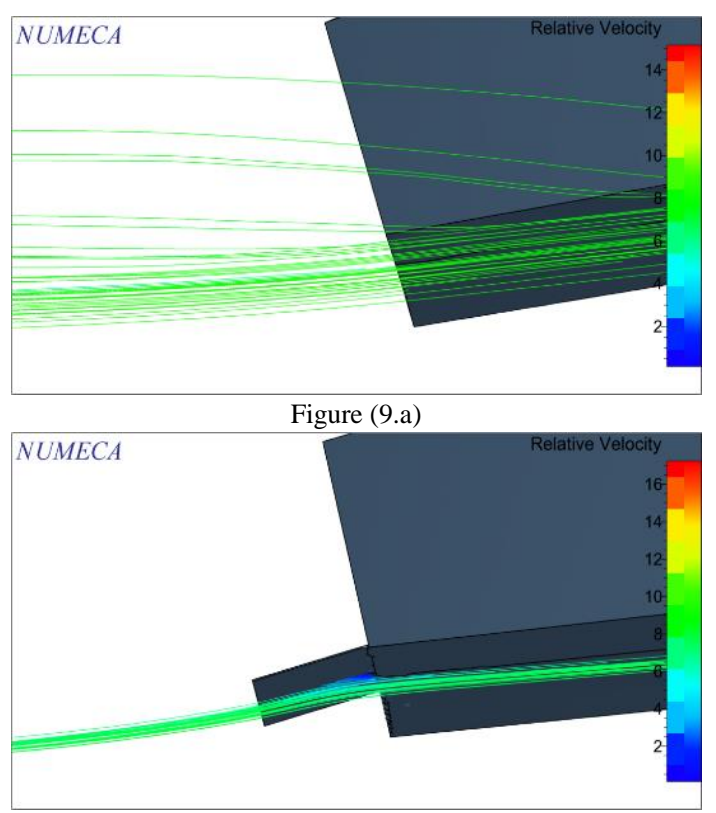

Figure (9.c)
In contrast to the previous condition, in the $10^{\circ}$ trim tab condition, the green color is slightly faded, and more and more vectors are light blue. This indicates that there are more areas where the flow velocity decreases. Further changes are shown in the condition of the $15^{\circ}$ trim tab, the blue color increasingly dominates the trim tab area which indicates more and more areas around the trim tab are run into a decrease in flow velocity.

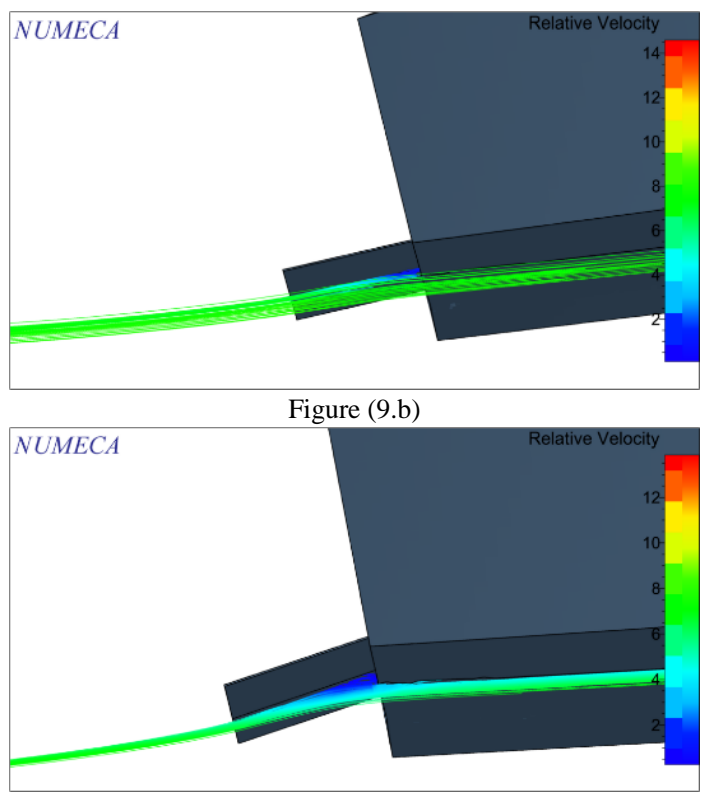

Figure (9.d)

Figure. 9. Relative Velocity at Fn 1.006 (a) Bare Hull (b) Trim Tab 50 (c) Trim Tab $10^{\circ}$ (d) Trim Tab $15^{\circ}$.

And at a speed of 19 knots or Fn 1.274 in Figure 10, it is found that in the bare hull, at the stern of the ship there is no bulge and the flow velocity tends to be constant, shown in green. In contrast to the condition of the 5degree trim tab, the light blue and dark blue colors

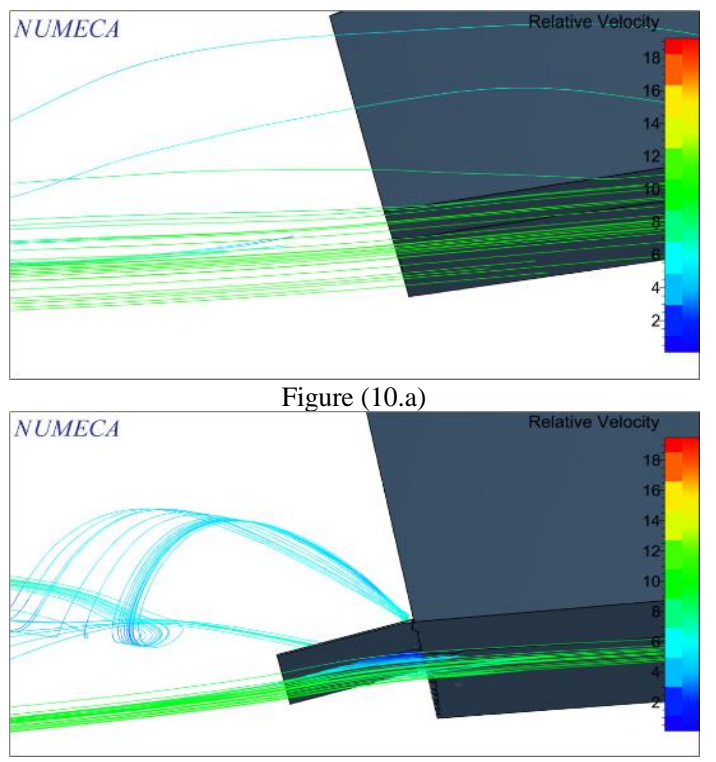

Figure (10.c)

Figure 10. Relative Velocity at Fn 1.274 (a) Bare Hull (b) Trim Tab $5^{\circ}$ (c) Trim Tab $10^{\circ}$ (d) Trim Tab $15^{\circ}$

The blue color that appears around the trim tab area can be said to be an eddy or fluid vortex whichs work to generate lift at the stern of the ship. In the condition of appear when there is a flow velocity right in front of the trim tab. Then in the 10-degree and 15-degree trim tab conditions, the blue color begins to dominate in the trim tab area, where the flow velocity is reduced to a lower level until it approaches 0 .
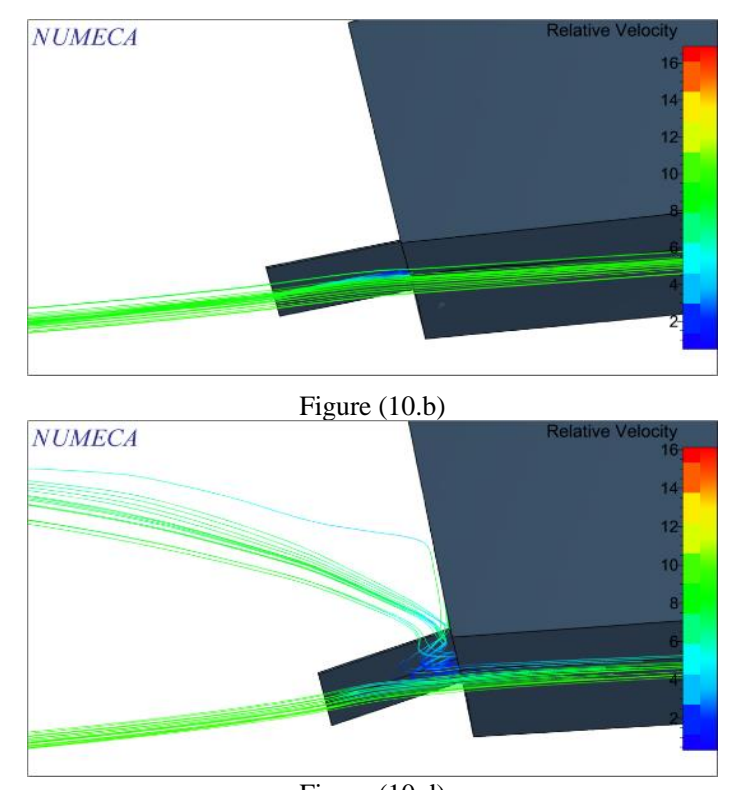

Figure (10.d)

the trim tab 10 degrees and 15 degrees also shows the air flow that expands to the side of the ship and kicks up, 
this is due to the large angle of the trim tab and consequently the high speed of the ship.

\section{Propulsion Power Requirement}

As explained in the previous sub-chapter that the higher the speed, the smaller the ship's resistance gain. However, in calculating the ship's propulsion power requirements, it becomes even greater. This is because the calculation of power requirements consists the parameters of ship resistance and ship speed.

Based on Table 4 and Figure 11, it was found that after the trim tab was installed, the propulsion power requirement of the ship could be reduced. In the condition of Fn 1.006, the ship's propulsion power was reduced to $57.915 \mathrm{~kW}$ with a reduction of $17.25 \%$. Then at the condition of Fn 1.140, the propulsion power of the ship was reduced to $64.695 \mathrm{~kW}$ with a reduction of $11.98 \%$. And at $1.274 \mathrm{Fn}$ condition, the ship's propulsion power has been reduced to $69.741 \mathrm{~kW}$ with a reduction of $11.56 \%$. From the discussion, it was found that based on the propulsion power requirement, the largest reduction in any speed variations that occur on the ship with a trim tab angle of $15^{\circ}$.

TABLE 4

SHIP PROPULSION POWER REQUIREMENT

\begin{tabular}{ccccc||ccc}
\hline \multirow{4}{*}{ Fn } & \multicolumn{4}{c||}{ BHP $_{\text {MCR }}(\mathrm{kW})$} & \multicolumn{3}{c}{ Reduction (\%) } \\
& $\begin{array}{c}\text { Bare } \\
\text { Hull }\end{array}$ & $\begin{array}{c}\text { Trim Tab 5 } \\
\text { deg }\end{array}$ & $\begin{array}{c}\text { Trim Tab } \\
10 \mathrm{deg}\end{array}$ & $\begin{array}{c}\text { Trim Tab } \\
15 \mathrm{deg}\end{array}$ & $\begin{array}{c}\text { Trim Tab 5 } \\
\text { deg }\end{array}$ & $\begin{array}{c}\text { Trim Tab } \\
10 \mathrm{deg}\end{array}$ & $\begin{array}{c}\text { Trim Tab } \\
15 \mathrm{deg}\end{array}$ \\
\hline 1.006 & 69.990 & 64.386 & 60.879 & 57.915 & $8.01 \%$ & $13.02 \%$ & $17.25 \%$ \\
1.140 & 73.504 & 68.300 & 65.965 & 64.695 & $7.08 \%$ & $10.26 \%$ & $11.98 \%$ \\
1.274 & 78.854 & 72.580 & 70.154 & 69.741 & $7.96 \%$ & $11.03 \%$ & $11.56 \%$ \\
\hline
\end{tabular}

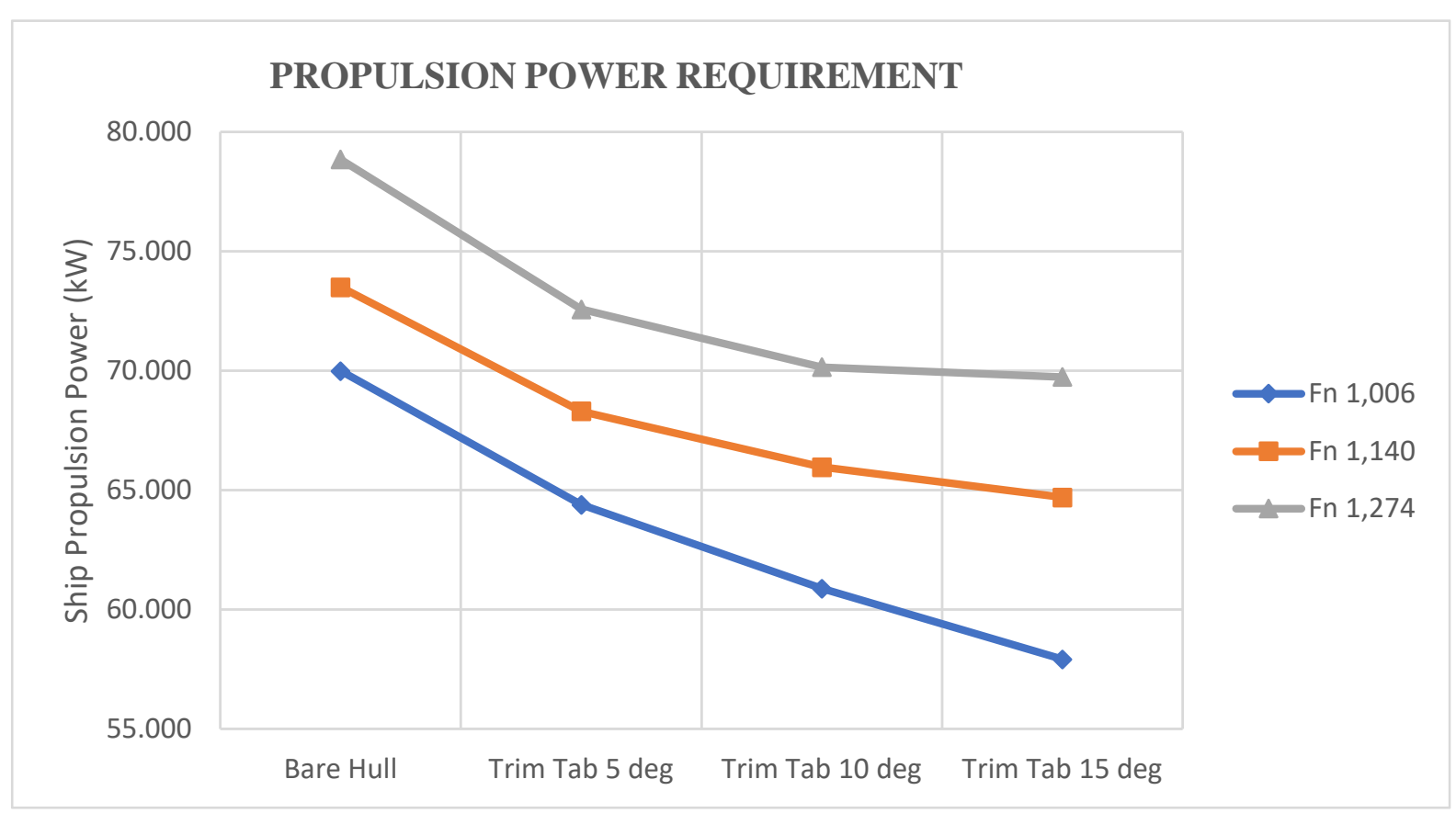

Figure 11. Ship Propulsion Power Requirement Graph

\section{CONCLUSION}

Based on the results of the analysis and simulations that have been carried out on a 6 meter speed boat regarding the impact of the trim tab installation and its angle variations, the following conclusions can be drawn as follow :

1. Based on the characteristics of the speed boat with a length of 6 meters and a single outboard engine configuration, the appropriate geometry is obtained which is a trim tab with a span width of 18 " (46 $\mathrm{cm})$ and a chord length of 9" $(23 \mathrm{~cm})$ and is installed at the stern of the ship.

2. After installing the trim tab with a size of $46 \mathrm{~cm} \mathrm{x}$ $23 \mathrm{~cm}$ on a 6 meter speed boat, it was found that there was an effect on the value of the resistance and trim of the ship. In general, the biggest change occurred in the condition of the $15^{\circ}$ trim tab on all speed variations. It is proven by the reduction of ship resistance up to $17.25 \%$ with a reduction from $3.872 \mathrm{kN}$ to $3.204 \mathrm{kN}$ which occurs at a speed of 15 knots. While the trim value of the ship, obtained a reduction of up to $46.72 \%$ with a reduction from $8.976^{\circ}$ to $4.782^{\circ}$ which also occurred at a speed of 15 knots.

3. After installing the trim tab with a size of $46 \mathrm{~cm} \mathrm{x}$ $23 \mathrm{~cm}$ on a 6 meter speed boat, it was found that there was a reduction in the propulsion power requirement of the ship. It can be concluded that the greater the angle of inclination of the trim tab, the smaller the required propulsion power of the ship. With details on the bare hull condition of 78.854 $\mathrm{kW}$, at $5^{\circ}$ trim tab angle of $72.580 \mathrm{~kW}$, then on the trim tab $10^{\circ}$ condition of $70.154 \mathrm{~kW}$, and at $15^{\circ}$ trim 
tab angle of $69.741 \mathrm{~kW}$ with the largest reduction reaching $11.56 \%$.

\section{REFERENCES}

[1] Chrismianto, Deddy dan Berlian Arswendo. (2014). "pengaruh variasi bentuk buritan kapal terhadap hambatan total menggunakan metode CFD". KAPAL Vol 11, No.3.

[2] Jang, Jinho, dkk. (2014). Experimental investigation of frictional resistance reduction with air layer on the hull bottom of a ship. Ocean Engineering, Pp. 363-379.

[3] Mansoori, M \& A.C. Fernandes. (2017). Interceptor and trim tab combination to prevent interceptor's unfit effectsᄀ. Ocean Engineering, 134, 140-156.
[4] B, Maria Margareta Z., dkk. (2016). "Pengaruh variasi sudut masuk trim tab pada fast patrol boat 60 meter menggunakan pendekatan CFD”.ISBN 978-602-98569-10

[5] Harvald, SV. AA, (1983). Resistance and Propulsion of Ship. Lyngby : John Wiley \& Sons

[6] Carlton, J.S. 2012. Marine Propellers and Propulsion. United Kingdom: Butterworth-Heinemann.

[7] Lewis, Edward V. 1988. Principles Naval Architecture Vol II. New Jersey: The Society of Naval Architects and Marine Engineers.

[8] D. Savitsky, Hydrodynamic Design of Planing Hulls, MARINE TECHNOLOGY, vol. 1, no. 71-95, p. 1, 1964. 